\title{
WORKING WITH DATA TABLES AND GRAPHS AT PRIMARY SCHOOL
}

\author{
Rumyana Y. Papancheva \\ University „Prof. Dr. Asen Zlatarov” - 8000 Burgas, Bulgaria \\ Faculty of Social Sciences \\ $+359888272944$ \\ papancheva@dgklaz.net
}

\section{Original Scientific Paper doi:10.5937/jouproman5-15373}

\begin{abstract}
The article presents a model for developing data handling competencies at Primary school. The work is part of a larger research aiming at forming basic statistic literacy at early ages. Data analysis knowledge and skills are important part for the nowadays person. At Primary school, some basic skills for data handling must be developed. Working with data structured in tables and presented by graphs corresponds with the process of developing students' digital skills. Experimental work was done at third grade of primary school in equipped with contemporary technologies learning environment. Some example tasks are presented and the results from the experimental work are analysed.
\end{abstract}

Keywords: statistical literacy at Primary school, data handling, tables and graphs, technologies integration, Primary school mathematics

\section{INTRODUCTION}

The rapid and permanent development of the computational technologies leads to the possibility of processing a vast amount of information, as well as its analysing, visualizing, and systematizing. A variety of information in tabular and graphic form fills the everyday life of the average person. One should be able to understand information presented by tables or graphs concerning food ingredients or the local or national election results, or the health status of a research, etc. The progress in technology and science leads to the increase of the need for the so-called statistical literacy - the ability to read and properly interpret information, presented in tabular or graphic form, as well as the skills to structure the gathered information in tabular or graphic form for its subsequent processing and analysis.
Recognizing the role of statistical literacy, many educational standards provide for its formation from primary school age (NCTM, 2000). This development demands specially educated primary school teachers (Estrella, 2015). The educational program in Mathematics in Canada, for example, includes a special section of probabilities and data analysis (Bardier,2002), (Bardier,2002), (Bilodeau, S. and all, 2010), (Bilodeau, S. and all, 2010). The first grade Math textbook (Bilodeau, S. and all, 2010) includes an explanation about the axes and the height of the bars in the diagram. The pupils themselves colour the correct height of the columns in prepared graphs.

According Bulgarian education standards students start working with data handling from 5 -th grade of Secondary school.

\section{WORKING WITH TABLES AND GRAPHS IN BULGARIAN PRIMARY SCHOOL}

The national educational standards for primary school mathematics don't include special part for data handling. In the educational content included in students' math textbooks and other teaching resources there are single problems, using tabular and graphic information of the following kind:

Problems, where tables with a given relation between rows and columns need to be filled in, and whose aim is to improve numerical skills of the students. 
After completing the tables, an analysis of the results is carried out, which aims at consolidating knowledge about properties of arithmetic operations such as monotony, identity property, etc.;

Problems for structuring text or image information in tabular form - typically problems including images are related to geometric figures (triangles, squares, rectangles) where students should determine the type of angles, the circumference, the area, the side length, etc.;

Single problems to formulate conclusions on data given in a table or through a diagram.

The textbooks in Mathematics in Bulgaria are under Ministry of education regulation. There are a set of approved textbooks distributed at national school system. The educational content concerning data handling could be summarized as follows: In the first grade, students determine the rows and the columns of the data table. They identify the position of an item into a table upon row and column intersection. Usually students must fill in addition or subtraction tables to improve their numerical skills and knowledge about operations - component names and some properties of addition and subtraction. Students compose and solve math word problems by a content given in a tabular form, combining pictures and numbers. This form for presenting the problem's content is especially suitable for the first graders who cannot yet read well. In the second grade, the text books in Mathematics include some problems, where students must fill in tables doing addition, subtraction, multiplication or division. Students compose word problems on information presented in a table. In the third grade, only one of the Math textbooks (Manova, 2003) includes a problem of analysing information presented by a diagram. The same situation is observed in mathematics textbooks for the fourth grade - they include some word math problems, given in tabular form, and some problems presenting the information through diagrams.

We cannot talk about the existence of a system of developing of initial literacy for working with tables and diagrams. To build basic statistical literacy it is necessary to build first some basic knowledge and skills to operate with tables and diagrams.

\section{APPLICATION OF MODEL FOR DATA HANDLING AT PRIMARY SCHOOL}

Forming skills for working with tables and diagrams goes through two main stages:

- Forming skills for reading information, given in a tabular or graphical form.

- Forming skills for presenting information in tabular or graphical form.

At the first stage, the student should be able to make conclusions on a given table or diagram. By using information, given in graphical or tabular form the student should be able to answer to the questions asked or to add missing information by additional calculations. At the second stage, the student should be able to present information, given in the form of a text in a table, and to be able to present it in the form of a chart.

\section{APPROBATION OF THE MODEL AT PRIMARY SCHOOL}

\section{THE EXPERIMENTAL FRAMEWORK}

The goal of the study is to clarify and to raise the level of understanding of the third-grade students of data handling and to build knowledge of working with data tables and graphs at Primary school.

The approbation process took place in technologies equipped learning environment. The teacher and students worked on an interactive whiteboard on specially designed learning tasks in digital form. Students worked as well on variety of worksheets on paper. Some of the tasks were done in working in pairs.

\section{PARAMETERS OF THE STUDY}

The target group was 3rd grade students (no indication for additional interest in mathematics among them) - two classes with 40 students. 
The experimental work lasted 6 academic hours distributed in the following manner: diagnostic test, one teacher's class of the weak, 3 Math classes, and control test.

Students worked collectively on problems proposed by the teacher. The teacher's class is one hour per weak where the teacher and the students discuss variety of problems, concerning different aspects of students' life at school and out of the school. Such a class is used as introduction activity to acquaint students with the topic of the work, and to motivate them for active work with data, tables and graphs. During math classes students solve problems concerning data handling. The learning content is divided in three parts: Part 1. Filling in tables by doing calculations. Understanding and interpreting data, presented in tabular form; Part 2. Writing text information in a tabular form; Part 3 . Understanding and interpreting data, presented by a chart.

\section{INDICATORS AND DATA COLLECTION}

The following indicators were used to determine the initial level of understanding the way of working with data from third-grade students:

\section{Working with tabular information}

Indicators:

- The student can fill in a table keeping the data dependence on rows and columns.

- The student can structure information, presenting it in tabular form.

- By using information given in graphical or tabular form, the student may calculate missing information in the table or into the diagram.

$\underline{\text { Working with diagrams }}$

Indicators:

- The student can interpret information, presented by a diagram.

- The student can use information from some diagrams to formulate a conclusion.
- The student can present the information from a tabular graphical view (via diagram).

The evaluation scale is given in Table 1. Adding a coefficient 2 gives an assessment of the performance of the students in the six-point system (according Bulgarian system of estimation, the excellent mark is 6) - from "weak" to "excellent" assessment.

\section{STATISTICS}

About the first criterion - work with tabular information - outbound diagnosis shows better results for students when structuring a given information in tabular form. $80 \%$ of the students work fully and correctly. Figure 1 on the diagram shows the comparison between the results of the incoming and the outgoing diagnosis according to criterion 1 , indication 2 (C1-I2).

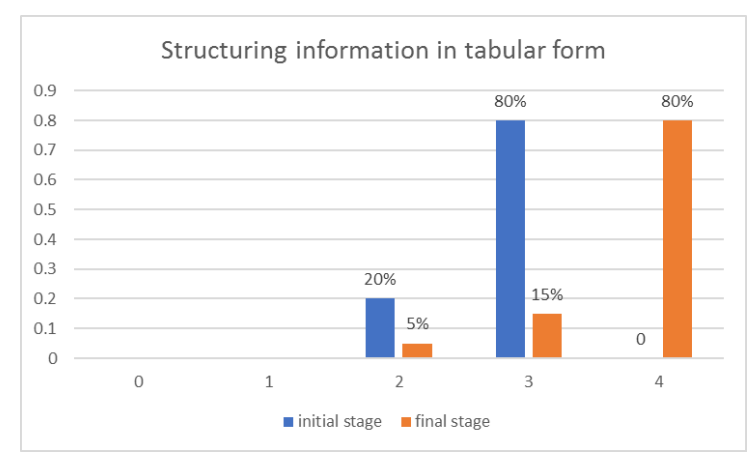

Figure 1. Comparison of results between incoming and outgoing diagnosis, C1-I2

About the second criterion - working with diagrams - at the end or the experimental work students are more confident to work with information provided by a chart. $60 \%$ of students interpret correctly the information, presented by a diagram. Figure 2 shows a comparison between incoming and outgoing results according to C2-I1. Outgoing diagnosis shows students' accurate work when dealing with problems requiring visualization of results given in a table via chart. $95 \%$ of students work correctly (60\% with evaluation points 4 , and $35 \%$ with evaluation points 3 ). 
The remaining 5\% make some minor mistakes. Figure 3 shows the progress of the students according using information from two, three and more diagrams to formulate some conclusions.

When speaking of motivation and willingness to work, it can be noted that pupils work with interest and approach the problems assigned to them as a logical task, a puzzle, a kind of conundrum, where they must find relation and present it from one type to another.

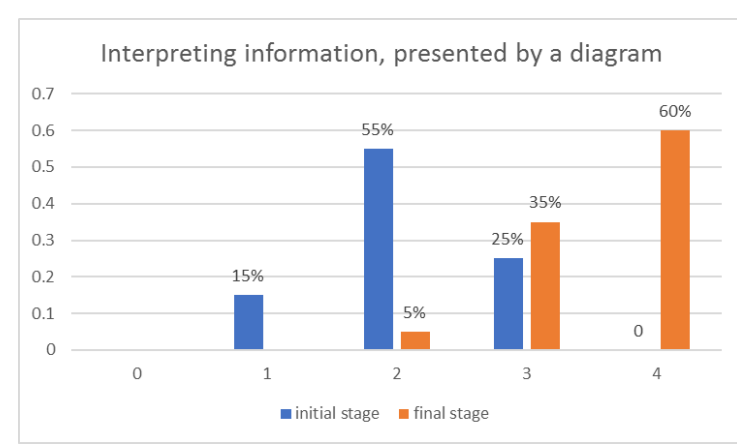

Figure 2. Comparison of results between incoming and outgoing diagnosis, C2-II

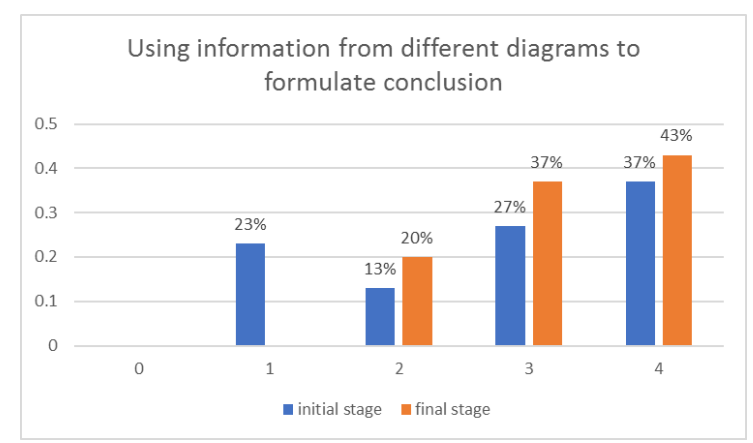

Figure 3. Comparison of results between incoming and outgoing diagnosis, C2-I2

Particularly appropriate is the use of interactive whiteboard tools. Through them, the teacher can solve and discuss many previously prepared problems in front of the class before switching to student work on their own. For example, students are provided with information in a table that they must turn into a chart. Example 1 gives information about the number of children who attended circus performances within one week. The information is given in a table to show the exact match - day of the week and number of students. The same correspondence should be transferred as a diagram. The diagram is outlined. Students are required to construct the rectangles vertically for each day of the week according to the number of students. The teacher demonstrates how to draw one of the pillars.

Example 1. In the first week of May in the town of Pleven there is a visiting circus. The number of students who attended the circus performances during the week is given in the table. Build a chart of the number of students who attended Circus Arena this week.

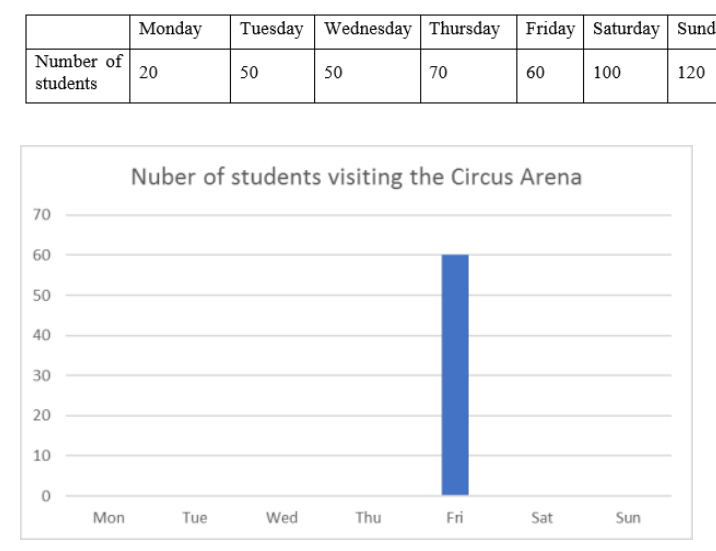

Figure 3 shows an example of electronic resources that provide the teacher with an interactive technology. Using a Pencil tool, the teacher and the pupils outline the pillars with height, according to the values given in the table. On the chart outlined, the teacher asks for additional questions to determine the level of understanding the problem - for example, on which day the circus is visited by most students, and on which day - by the least number of students. With the Marker tool, you can additionally mark the columns, answering the questions asked by the teacher.

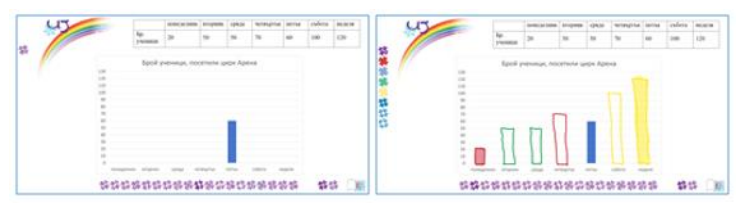

Figure 3. Exemplary electronic resources to form knowledge and skills for diagrams drawing 


\section{CONCLUSIONS}

Forming knowledge and skills to work with tables and charts involves the following stages:

1. Propaedeutics of working with tables in the kindergarten and first grade of Primary school.

2. Working with tables for forming and developing computing skills of students.

3. Understanding and interpreting data set in tabular form.

4. Writing text information in tabular form.

5. Understand and interpret data diagrams

6. Presenting information in tabular form through a chart.

The process of forming knowledge and skills for working with tables and charts is effectively illustrated when using interactive hardware and software technologies. When combined with a game-based approach, quality learning outcomes are achieved.

\section{REFERENCE}

[1] NCTM (2000), Principals and standards for school mathematics. Reston, VA: NCTM

[2] Estrella, Soledad, Olfos, Raimundo, \& Mena-Lorca, Arturo. (2015). Pedagogical knowledge of statistics content among primary school teachers. Educação $e$ Pesquisa, 41(2), 477-493. https://dx.doi.org/10.1590/s151797022015041858

[3] Bardier, J.-C., 2002. Clickmaths. Mathematiques $\mathrm{Au}$ Primaire. Cahier D'Execices 4. Laval (Quebec): Editions Grand Duc.

[4] Bardier, J.-C., 2002. Clickmaths. Mathematiques au primarire. Cahier Dexercices 3. Laval (Quebec): Editions Grand Duc.

[5] Bilodeau, S., Dumont, C. \& Loubier, K., 2010. Math et Matie. Cahier d'apprentissage A. Anjou (Quebec): Les Editions CEC.

[6] Bilodeau, S., Dumont, C. \& Loubier, K., 2010. Mathe at Matie. Cahier d'apprentissage B. Anjou (Quebec): Les Editions CEC.

[7] Manova, A, Rangelova, R, Garcheva, Y, Mathematics for 3rd grade, Sofia, Prosveta, 2003.

\section{ACKNOWLEDGMENTS}

The article is part of a study of the author under project DN 05/8 14.12.2016, funded by the Bulgarian National Science Fund on „Digital Competencies and Media Education at Pre-school and Primary School Age “.

Table 1 Assessment scale used in the research

\begin{tabular}{|l|l|l|}
\hline POINTS & A S S E S S M E N T R A T E S \\
\hline 4 & high & The student works fully and correctly. \\
\hline 3 & good & The student works truly but not fully. \\
\hline 2 & medium & The student works partially correctly. \\
\hline 1 & low & Works wrong. \\
\hline 0 & weak & Does not work. \\
\hline
\end{tabular}

